\title{
Gonzalo Núñez, Rubén Darío y el manuscrito Los arcanos de la música
}

\section{Gonzalo Núñez, Rubén Darío and the Manuscript Los arcanos de la música}

\author{
Alberto Hernández-Banuchi \\ Hunter College, the City University of New York, Estados Unidos \\ ahernandezbanuchi@gmail.com
}

\section{RESUMEN}

Examinamos los eventos y circunstancias en la vida del compositor puertorriqueño Gonzalo Núñez (1850-1915) durante el periodo de 1900 a 1903. En esta su segunda estadía en París cultivó una estrecha relación personal con Rubén Darío y Amado Nervo, junto a otros poetas, escritores y artistas. Un extenso trabajo de investigación in situ por varias bibliotecas y archivos europeos, norteamericanos y caribeños ha dado como resultado la recopilación de documentos sobre la vida nomádica del músico en Cuba, México, Puerto Rico, Europa y Norteamérica. Comprobamos que Los arcanos de la música, manuscrito inédito de Núñez - conservado en el Archivo de la Música y Sonido de Puerto Rico-, es la fuente principal de dos importantes crónicas de Rubén Darío.

\section{Palabras clave}

Gonzalo Núñez, Los arcanos de la música, Rubén Darío, Amado Nervo, Emanuel Swedenborg.

\section{ABSTRACT}

We examine the history and circumstance in the life of Puerto Rican composer Gonzalo Núñez (1850-1915) during the period from 1900 to 1903. During his second sojourn in Paris he maintained a close personal relationship with Rubén Darío and Amado Nervo, joined by other poets, writers and artists. An extensive on-site research work, conducted in various European, North American and Caribbean libraries and archives, permitted us to gather documentation about the nomadic life of the musician in Cuba, Mexico, Puerto Rico, Europe and North America. We show that Núñez's unpublished manuscript Los arcanos de la música, housed in the Archive of Music and Sound of Puerto Rico, is the main source of two important articles by Rubén Darío. 


\section{KEYWORDS \\ Gonzalo Núñez, Los arcanos de la música, Rubén Darío, Amado Nervo, Emanuel Swedenborg.}

RECEPCIÓN: 28/06/2020

ACEPTACIÓN: 28/07/2020

\section{Preludio}

J'ai plus des souvenirs que si j'avais mille ans, ${ }^{1}$ dice un verso de Baudelaire. A mí me pasa otro tanto; pero aun cuando viviese el doble de ese milenario acumulador de recuerdos, aun cuando tuviese más recuerdos que si hubiera vivido dos milenarios, no olvidaría jamás el extraño personaje que es objeto de estas notas, y por no sé qué azar encontré en mi camino.

Creo que Rubén Darío me lo presentó en el tiempo, ¡ay!, ya lejano en que los dos vivíamos en el número 29 del faubourg Montmartre, una de las calles más endiabladas y ruidosas del endiablado y ruidoso (y divino) París.

-El maestro X.

- Servidor de usted.

Era o es, porque todavía vive (salvo error u omisión), un hombre corpulento, muy moreno, caído de hombros, y que así por el cuerpo como por el corte de cara, se parecía notablemente a Balzac. Un Balzac más obscuro. Esta observación la hicimos al propio tiempo Darío y yo.

-El maestro X.

- Para servir a usted (Nervo, 1967, t. 1: 1476).

sí da comienzo una de las crónicas de viaje del poeta Amado Nervo, quien
fungía desde Europa como corresponsal de uno de los diarios mexicanos. Pero, ¿quién es el maestro X?, ¿qué relación, si alguna, se desarrolla entre ellos? Intentemos dilucidar el encuentro y significado entre ambos, pero antes establezcamos la documentación que se usará en este escrito.

Durante un trabajo de investigación postgraduado en varios archivos y bibliotecas, hemos encontrado una variedad de recursos bibliográficos que vinculan la personalidad del compositor puertorriqueño Gonzalo Núñez (1850-1915) con la del poeta nicaragüense Rubén Darío (1867-1916). ${ }^{2}$ El que capta la atención del investigador, y a su vez resulta el más raro y consecuente para este escrito, es un manuscrito inédito de Núñez titulado Los arcanos de la música, depositado en el Archivo General de Puerto Rico. Este tratado no pertenece a la literatura científico-musical habitual, porque es,

1 "Tengo más recuerdos que si tuviera mil años" [las traducciones de este artículo son mías]. Este es el primer verso de uno de los cuatro poemas titulados Spleen de Charles Baudelaire.

${ }^{2}$ Véanse las obras de Darío incluidas en la bibliografía. 
más bien, un tratado de teoría de la música desde un punto de vista místico y religioso. El mismo autor afirma en su libro que la teoría y sus nuevas leyes, a las que llama arcanos musicales, le fueron reveladas por Dios. ${ }^{3}$ Es un libro complejo, pero significativo, que nos ofrece la oportunidad de comparar varias de sus secciones y contraponerlas con algunos textos que Rubén Darío envió desde París para su publicación en las columnas de La Nación de Buenos Aires entre la primavera de 1900 y el verano de 1903.

En dichos escritos, Darío introduce a sus lectores con otros dos colegas mutuos, el poeta mexicano Amado Nervo y el pintor belga Henry de Groux. Debido a una producción literaria aneja de ensayos, cartas, crónicas, episodios e incidentes, podemos vincular al cuarteto y acercarnos a sus vivencias en la Ciudad Luz. Es Amado Nervo el miembro del cuarteto que mejor lo facilita; continuemos con el encuentro del enigmático músico a quien el poeta mexicano le confiere el epíteto Swedenborg:

Díjome que en México me había conocido; y yo recordé, como en sueño, al autor de una danza, de una leyenda melódica y de otras cosas muy bellas, de un romanticismo amable, que aquel hombre tocaba y gesticulaba al propio tiempo con movimientos de músculos faciales, de hombros y de cabeza.

- Compone usted cosas muy hermosas - le dije.

Pero mi cumplido no le gustó. Swedemborg y los yanquis habíanle vuelto apóstol ni más ni menos al que yo tenía delante. Su devoción por el iluminado escandinavo nos hizo darle su nombre y con tal nombre lo presentamos a Don Justo Sierra cuando estuvo en París. Quedándose éste, mi eminente amigo, tan intrigado como Darío y yo ante la enigmática personalidad del maestro.

- La música... - me respondió. Sí, pero no esta que toco; eso no es nada. El piano... ¡fu! Usted no sabe que he inventado una teoría musical que va a revolucionar el mundo entero (Nervo, 1967, t. 1: 1476-1477).

\section{La nueva Jerusalén}

Ocupémonos del escrito dariano que nos ofrece la primera oportunidad de una comparación textual elaborada por el dúo Darío-Núñez. "La nueva Jerusalén", incluido en su obra Peregrinaciones, relata un evento ocurrido la tarde del domingo 8 de enero de 1901. En una de sus frecuentes visitas a la residencia del compositor amigo, Darío, el perenne inquisidor de asuntos misteriosos (Torres, 1980: 479) — y podemos añadir, para evitar ir solo-, invita a su nuevo guía en asuntos del au-delà para que le acompañe hasta el Quartier Latin, donde se celebraría un servicio religioso de mutuo interés. Antes de

\footnotetext{
${ }^{3} \mathrm{Al}$ final del texto principal del tratado, en el capítulo "La Trinidad", y resumiendo las nuevas leyes expuestas en su libro, el autor admite: "No me extrañaría que el mismo fenómeno se reproduzca en los que leen por primera vez las Revelaciones precedentes. En la calma y la meditación encontrarán su grandeza, pues esta fué mi impresión primera cuando el Señor tuvo a bien iluminar mi mente con esas Verdades" (Núñez, s. f.: 222).
} 
emprender dicho peregrinaje, una larga caminata desde Port Royal, el poeta "había visto en el New Tork Herald que el servicio era público y que se efectuaba el primero y tercer domingo de cada mes" (Darío, 1901: 110). En un anuncio, probablemente muy similar al que leyeron los dos amigos, se divulgaban los servicios quincenales inspirados por el pensamiento de Swedenborg, bajo la columna Church Services for To-Day, aparece: "NEW CHRISTIAN TEMPLE OF JERUSALEM, 12 rue Thouin, Pantheon. Worship and study of the inner meaning of the Holy Scriptures, according to E. Swedenborg. Sundays at 4 p.m. Mr. Ackroyd, Pastor. Every second Sunday of the month, worship in English at the same hour" (The New York Herald, 7 diciembre 1905: 10F). ${ }^{4}$

Darío relata que una vez finalizado el culto y:

Concluido el comento de la Biblia, el pastor hace una seña, y el armónium ataca un himno cristiano que los asistentes corean con más o menos afinación. Yo dirijo la vista alrededor. ¡Somos muy pocos! Y, prudentemente, expongo a mi acompañante mis temores de un escaso éxito neohierosolimitano. Pero él, bravo varón de fe, me contesta en español que pudo ser oído de toda la asistencia. - “iNo importa! Con menos gente empezó su iglesia Nuestro Señor Jesucristo!” (Darío, 1901: 112).

Núñez presenta a Darío, como un nuevo adepto, al reverendo Hussener y a la sacerdotisa norteamericana fundadora del pequeño oratorio Madame Humann. Al día siguiente, aprovechando la oportunidad de esparcir su doctrina por América del Sur a través de su nuevo prosélito, el pastor no vacila en enviar una carta a Darío, en la que le ofrece detalles sobre la Nueva Iglesia, la del Segundo Advenimiento del Señor, y le aclara que "No somos ni una secta del protestantismo, ni una rama cualquiera del catolicismo: somos una viña nueva plantada por el Señor para regenerar el mundo y conducirle a Dios" (Darío, 1901: 119). Pero Darío, con la intención de despejarse de tal apostolado, declara a sus lectores: "Vagamente sospecho que se me ha querido convertir en el Jonás de la República Argentina. Pongo, con modestia, mi dimisión, y dejo el puesto para otro que lo quiera tomar" (Darío, 1901: 119).

Tanto en Europa como en América, la corriente de pensamiento esotérico-espiritista había despertado el interés entre los intelectuales del siglo decimonono, en particular había dejado un rastro irrebatible en la obra de docenas de artistas y poetas franceses reconocidos. Al respecto, Honoré de Balzac había declarado en su novela Louis Lambert que Swedenborg "résume toutes les religions, ou plutôt la seule religion de l'Humanité" (Balzac, 1855 : 171)..$^{5}$ Mientras que Charles Baudelaire, junto a tan-

4 "NUEVO TEMPLO GRISTIANO DE JERUSALÉN. 12 calle Thouin, Pantheon. Adoración y estudio del significado de las Sagradas Escrituras, según E. Swedenborg. Domingos a las 4 p.m. Pastor Ackroyd. Cada segundo domingo del mes, adoración en inglés a la misma hora".

5 "resume de todas las religiones o, más bien, la única religión de la humanidad". 
tos otros literatos conocidos, era ávido lector de las obras arcanas del teólogo sueco. La Ciudad Luz se había convertido en la cuna y foco de este movimiento espiritual europeo cuando el educador Allan Kardec (1804-1869), cautivado por los fenómenos paranormales, dio a conocer su Livre des Esprits en 1857, seguido por su publicación periódica Revue Spirite un año más tarde. Aún más reciente a la fecha de los acontecimientos de nuestros ilustres en París, se habían celebrado dos importantes cenáculos: el Congreso Internacional Espiritista y Espiritualista en 1889 y el Congreso de París en 1900 (Méndez, 1927: 515-533). El tema, ni desconocido en la prensa local ni en conversaciones de la sociedad parisina francesa, no escapó de la atención de Darío (Acereda, 2005: 423-444). Sobre su interacción con amigos ocultistas, éste informa a sus lectores de La Nación ese noviembre:

Debo advertir que creo en absoluto en la sinceridad de mi amigo. Á pesar de que muchas veces he oído de sus labios, narraciones, sucesos y hechos personales que parecerían increíbles, no me han sorprendido tanto, después de haberme dedicado, en otros tiempos, á lecturas teosóficas y ocultistas. Las historias y experimentos de Núñez, ${ }^{6}$ no me parece que sobrepasen á lo que todos conocemos de William Crookes, H. P. Blavatsky, Richet, Lombroso, y tantos otros. Núñez es un ocultista cristiano; y repito es un hombre sincero. Es este principal valor de su opinión (Darío, 2000: 174-176).

Pero luego, en su autobiografía, Darío apunta hacia un cierto distanciamiento de esas cosas:

Como dejo escrito, con Lugones y Piñeiro, Sorondo hablaba mucho sobre ciencias ocultas. Me había dado desde hacía largo tiempo a esta clase de estudios, y los abandoné a causa de mi extremada nerviosidad y por consejo de médicos amigos. Yo había, desde muy joven, tenido ocasión, si bien raras veces, de observar la presencia y la acción de las fuerzas misteriosas y extrañas, que aún no han llegado al conocimiento y dominio de la ciencia oficial. En Caras y Caretas ha aparecido una página mía, en que narro cómo en la plaza de la catedral de León, en Nicaragua, una madrugada ví y toqué una larva, una horrible materialización sepulcral, estando en mi sano y completo juicio.

$[\ldots]$

He contado también los casos de ese género, acontecidos a gentes de mi conocimiento. En París, con Leopoldo Lugones, hemos observado en el doctor Encausse, esto es, el célebre Papus, ${ }^{7}$ cosas interesantísimas; pero según lo dejo expresado, no he seguido en esa clase de investigaciones por temor justo a alguna perturbación cerebral (Darío, 1915: cap. XLVI).

${ }^{6}$ Debemos apuntar que la obra cumbre del teólogo sueco se titula Arcanos celestes (Arcana coelestia, 1749-1756), y la de Núñez, Los arcanos de la música; su cita "La música no es un arte ni una ciencia, es una revelación", referida en el capítulo "La Trinidad" de dicha obra, dilucida este hecho (Núñez, s. f.: 145).

${ }^{7}$ Papus, seudónimo de Gérard Encausse (1865-1916), conocido médico y ocultista francés, divulgador del ocultismo. 
Amado Nervo, que había conocido al músico ocultista, le asigna por primera vez el epíteto cuando escribe al amigo Quintanilla en enero: "Hermano mío: Swedenborg es demasiado ingenuo: le llama al cielo el grandísimo hombre y cree que tiene vejiga urética y... todo el negocio" (Nervo, 1967, t. 2: 1147). Pero nótese que su contacto con el espiritismo era anterior a su llegada a París, cuando experimentó y luego reportó sobre una reunión espiritista con un niño médium (a quien se le llama facultad) de escasos ocho años de edad en casa de un indio, ubicada en un callejón de la Ciudad de México. Entonces prosigue:

Como era domingo, la sesión estaba destinada a las manifestaciones fisicas [...]

Los fieles iban acudiendo: viejecitos de fisonomía dulce y de levita negra, charros, muchachas pobres, ancianas enlutadas, algunos enfermos, todos del pueblo o tal cual chiquitín pegado a las faldas de su mamá. La gran mayoría de los asistentes estaba integrada por la clase humilde de la capital, y todos dejaban ver a las claras el respeto que los poseía.

Tomé asiento en una banca [...] a tiempo que surgía de un rincón el bordoneo de una guitarra, al compás de la cual voces de devotas, cantaban himnos adaptados a las tonadas de la Golondrina y de la Casada.

$[\ldots]$

Instintivamente seguía con la cabeza el compás de las místicas coplas que con la música de la Casada se entonaban; y como todos las cantaban a coro, y el fervor es contagioso, acabé por cantar también (Nervo, 1967, t. 1: 447-448; las cursivas son del autor).

Una breve biografía sobre Amado Nervo, accesible en Internet, revela otros datos aún más interesantes y significativos:

El dato biográfico más importante de su estancia en París es su encuentro con Ana Cecilia Luisa Dailliez, el gran amor de su vida, a quien dedica el poemario por excelencia del Eros y Thanatos del modernismo: La amada inmóvil, tal vez el poemario más leído, aunque no el mejor, de Nervo (Méndez Plancarte). Según Durán (por cita de Hernán Rosales) Ana era hija de un teósofo que tenía una librería especializada en ciencias ocultas e invitó a él y a Darío a sesiones teosóficas que él mismo presidía. Una circunstancia que explica el interés de Nervo por fenómenos como la transmigración o el espiritismo reflejado, sobre todo, en las citas del poemario (Oviedo: $\S 7) .^{8}$

Las notas de Amado Nervo sobre su convivencia con Rubén Darío, Gonzalo Núñez y Henry de Groux tienden a ser detalladas, a veces llenas de humor y hasta cinismo, ofreciéndonos una faceta más íntima del cuarteto. Después del encuentro en enero, la relación es ya más cercana, como le confiesa a Quintanilla el 9 de febrero:

\footnotetext{
${ }^{8}$ Este hecho se encuentra en la obra de Manuel Durán Genio y figura de Amado Nervo (Durán, 1968: 75), que, a su vez, cita a Patricia Morgan, "Amado Nervo, su vida y su obra" (Atenea, número XXXII, mayo de 1955, 204-205).
} 
Swedenborg, es decir, Núñez, sigue invitándome a comer. No tiene ni un centavo, pero como buen artista es espléndido. A veces, después de haber pasado con él toda la tarde, todavía nos detiene a cenar. Entonces Rubén y yo vamos a comprar cualquier cosa; paté foi-gras, bupas à la mode, etc., ${ }^{9}$ para contribuir con algo...; la señora y las muchachas las cocinan, y comemos; entre bocado y bocado, exégesis del Evangelio. Por supuesto que, lejos de convencernos, el pobre pierde sus estribos. Es un excelente hombre, y sus hijas, muy agradables (Nervo, 1967, t. 2: 1149).

En una carta subsiguiente del 21 de marzo, Nervo reitera las frecuentes cenas en la casa del músico en compañía de Darío: "De Groux me ha preguntado por ti: naturalmente le di tus recados. Swedenborg (Núñez) sigue muy amigo de Rubén y mío. Por lo menos, dos veces a la semana comemos en su casa. (Su mujer guisa muy bien.). Los días de Carnaval, Rubén y yo paseamos a las muchachas por el boulevard" (Nervo, 1967, t. 2: 1150; las cursivas son del autor).

La relación entre Nervo y la familia Núñez, a diferencia de Darío, es fluctuante; en aquel primer encuentro: "¡Quién sabe! Aquel hombre tenía mucho talento, se parecía a Balzac, y era muy bueno" (Nervo, 1967, t. 1: 1477), pero a finales del mes de enero el tono ha cambiado drásticamente: "No quiero volver a esa casa en algún tiempo y menos que Rubén vuelva. Quizá haríamos... bien” (Nervo, 1967, t. 2: 1148). Finalmente, en junio, escribe a Dieppe: "Muy querido Rubén: No se alarme por el papel de luto. Ni usted ni yo nos hemos muerto, por más que Swedenborg crea a veces lo contrario" (Nervo, 1967, t. 2: 1130). ${ }^{10}$

Es muy probable que la razón del distanciamiento de Nervo con la familia Núnez se deba al tipo de relación que surge de parte del poeta mexicano con Adelina, la hija mayor del compositor. ${ }^{11}$ En su poema "Para Adelina Núñez" ${ }^{12}$ se percibe cierta atracción sensual del poeta, como luego confiesa a Quintanilla:

Hermano muy amado:

Tengo muchas cosas que contarte. [...]

Y tienes que después vino el swedenborgiano Núñez. Ya Darío habíame dado a leer un libro del iluminado escandinavo; no me convenció. No tengo tiempo para tantas religiones nuevas: estoy muy ocupado. Y luego ese buen Swedenborg cree que los ángeles tienen

\footnotetext{
${ }^{9}$ Bupas à la mode podría ser un error de transcripción, por repas à la mode (comida al estilo de...), aunque faltaría especificar el estilo: à la mode du pays, à la mode arabe, auvergnate, périgourdine, anglaise, espagnole, etc.

${ }^{10}$ No se ha encontrado documentación que vincule a Nervo y a Núñez después de su partida en 1902.

${ }^{11}$ Núñez tenía otras dos hijas: Helen (n. 1890) y Trinidad (n. 1893).

${ }^{12}$ Concluye el poema: "las rosas más bermejas/ que tus mordiscos, y las violetas más violetas./ Será tu esposo el ángel que tu ideal incova,/ y el alma de los mundos te besará en la boca,/ y cantarán tus nupcias divinas de poetas” (Nervo, 1967, t. 2: 1357).
} 
un cuerpo y comen y hablan y... todo. Très au plaisir, mon vieux, mais.... [sic $]^{13} \mathrm{Y}$ me llevó a su casa Núñez; fuimos Rubén y yo y conversamos y comimos, y yo hablé, ¿a quién?, a la muchacha mayor de la casa; diez y ocho años y cien palideces. Y, naturalmente, de todas las teorías de Núñez la más que me gustó fue la muchacha pálida. Y le hablé a la muchacha pálida del derecho a la vida, al sol, al agua, al amor; y le dije lo suave que eran las sedas y lo fulgurante que eran las gemas y qué bellamente temblaban en el pecho pálido de una suave mujer pálida. Después tuve remordimientos (Nervo, 1967, t. 2: 1147-1148).

¿Pero qué más sabemos de Gonzalo Núñez y su familia? ¿Qué bagaje artístico o intelectual remolca consigo el músico? ¿Por qué razón cautiva tanto al poeta mexicano como al nicaragüense?

\section{Bosquejo biográfico}

Parece ser uno de los cientos de planetas darianos en órbita. Gonzalo Carlos de Jesús Núñez Rivera nace en Bayamón, pueblo vecino de la ciudad capital de San Juan de Puerto Rico, en 1850. ${ }^{14}$ El historiador Fernando Callejo indica que el joven estudia piano con el pedagogo catalán residente en San Juan, José Cabrizas ${ }^{15}$ (Callejo, 1915: 141-144). Pero no satisfecho con el progreso en el instrumento decide irse a París en 1868 en busca de una técnica pianística depurada y, a su vez, con el objetivo de ampliar sus horizontes intelectuales. Lutecia le acoge, y pronto localiza a dos excelentes y prestigiosos maestros de música, el pianista Félix Le Couppey (1814-1887) y el profesor de teoría Augustin Savard (1814-1881). ${ }^{16}$ Según Del Valle, ambos le reciben en sus respectivos estudios privados por cuatro años (Valle, 1905: 15). Sin embargo, apenas 18 meses después de su llegada, le sorprenderán la guerra franco-prusiana (19 de julio de 1870 al 10 de mayo de 1871) y La Comuna de París (18 de marzo al 28 de mayo de 1871).

Pasados los disturbios, cuando la ciudad recobró su normalidad, el joven Gonzalo Núñez se prepara, audiciona y es admitido en el Conservatorio Imperial de la Música

13 "Con mucho gusto, viejo, pero..."

14 "Certificación de Bautismo", Arzobispado de San Juan, Libro 17, Folio 162v, Iglesia Catedral. Fecha del bautismo 12 de agosto de 1850, con fecha de nacimiento el 7 de junio 1850.

${ }^{15}$ Por un error, el nombre del maestro de piano mencionado es "Juan", y no José, como es lo correcto. Al día de hoy, representa el compendio histórico de la música de Puerto Rico más completo, pero carente de documentación (referencias y citas bibliográficas).

${ }^{16}$ Ambos fueron profesores del Conservatorio Imperial de la Música, así como prolíficos autores de cuadernos y métodos de enseñanza de fama. Le Couppey ingresó a sus 17 años como ayudante de la clase de Armonía y Piano en 1831, y permaneció hasta 1887; por su parte, Savard se incorporó en 1841 y contó entre sus discípulos con los futuros compositores franceses Jules Massenet y Cécile Chaminade y el estadounidense Edward MacDowell. 


\section{Núñez, Darío y el manuscrito Los arcanos de la música}

en octubre de 1872. ${ }^{17}$ Cabe señalar que su nuevo maestro, el profesor George Mathias (1826-1910), era un excelente intérprete y pedagogo que, eventualmente, se convertirá en una de las más grandes figuras del arte pianístico, como portador de la tradición romántica heredada de su propio maestro, Federico Chopin (Methuen-Campbell, 1992: 194-196)..$^{18}$

Durante los próximos dos semestres de estudios de piano y de armonía, nuestro adolescente logra un progreso admirable, y al final del curso se prepara para el examen anual compulsorio. ${ }^{19}$ Lleno de confianza por sus excelentes calificaciones en esta prueba, Núñez, no conforme, se anima a competir por los codiciados premios del Conservatorio. Las competencias se celebraban anualmente ante un jurado de peritos y frente al público parisino. El obtener uno de los premios conllevaba cierta garantía para una exitosa carrera profesional. Junto a sus maestros y compañeros, Gonzalo Núñez se presenta ante los exigentes jueces, pero, en esta ocasión, deciden no otorgarle el primer premio. ${ }^{20}$ Una vez comenzada la nueva sesión académica, perdemos el rastro de nuestro aspirante en París. ${ }^{21}$

${ }^{17}$ Núñez aparece identificado en varios documentos del Conservatorio Nacional de Música entre los años 1872-1873, depositados en los Archivos Nacionales de París, Serie AJ37: aspirante a la clase de Piano y auditor de la clase de Harmonie écrite (armonía) de M. Savard, 31 de julio de 1872 (AJ37.327, 15); "Listas de aspirantes" (AJ37.283, AJ37.333, 7); "Registro de Inscripción" (AJ37.354, 1873, 162); "Gonzalo Núñez dans la classe de piano de M. Mathias", "Clases anuales, 2. a serie", "Profesores y estudiantes", martes 22 de octubre de 1872 (AJ37.158, 274).

${ }^{18}$ Mathias transmite los conocimientos de su maestro a varios estudiantes y futuros pianistas de fama internacional: Raoul Pugno, a quien encontraremos más adelante, Isidor Philipp y Ernest Schelling; el crítico James Huneker; los compositores franceses Erik Satie y Paul Dukas, además del español José Tragó, el bonaerense Alberto Williams y la caraqueña Teresa Carreño.

${ }^{19}$ En el registro, "Concurso o exámenes, semestral y de fin de curso", aparece como participante núm. 20 del examen, 29 de enero de 1873 (AJ37.238); participante número 21, examen 11 de junio de 1873 (AJ37.354, AJ37.162).

${ }^{20}$ La información biográfica existente del artista sobre este incidente es contradictoria, con base en las numerosas reseñas y críticas documentadas. Por ejemplo, según Serafín Ramírez y Padilla de Sanz le otorgan un primer premio, y en la reseña de su debut estadounidense se le atribuye un grado de dicha institución ("A New Pianist", 1877: 5B). El mismo autor de esa reseña, quien había transmitido este hecho, pudo corroborar más tarde que Núñez no obtuvo premio alguno de acuerdo con el corresponsal Pougin, quien, presente en dichas competencias, escribió: "J'ai dit que le concours masculin avait été beaucoup moins brillant; il était d'ailleurs moins nombreux. En l'absence d'un lutteur capable de remporter le premier prix, deux seconds prix ont été décernés" (Pougin, 1873: 150) [“Dije que la competencia masculina (en la categoría de piano) había sido mucho menos exitosa, también había menos de ellos. En ausencia de un luchador capaz de ganar el primer premio, se otorgaron dos segundos premios"].

${ }^{21}$ Núñez no aparece incluido en la lista de estudiantes del curso de 1873, pero sí se encuentra la anotación "rayé ler octubre 1873", o sea que dimitió el primero de octubre de 1873 (AJ37.97), y no continuó ni obtuvo grado o diploma alguno en dicha institución. 
Nuevamente, ubicamos al joven pianista en la Ciudad de México cuando participa, junto al afamado violinista cubano José White, en un recital reseñado por José Martí en junio de 1875 (Martí, 2010: 71), y luego en su gira por Cuba entre 1875-1876 (Ramírez, 1891: 489). Su introducción al público estadounidense ocurre en diciembre de 1877 ("A New Pianist", 1877: 5B); dos años más tarde, contrae matrimonio y se establece en la urbe neoyorquina. ${ }^{22}$ Durante su carrera profesional, alcanza críticas favorables tanto por su precisa ejecución como por su autoría de obras para piano. Pero, hacia los últimos años de la década de 1880, su situación económica le obliga ocasionalmente a aceptar colocaciones temporales fuera de su ciudad de residencia, y comienza una vida de nómada: en el Colegio de Arte y Música de Kentucky (verano de 1888) y en el Colegio de Música de Toronto en Canadá (otoño e invierno en 18981899); tournées en su tierra natal (1892), Cuba (1894) y México (1895).

\section{Cosas de Orfeo}

“Es un iluminado? ¿es un tocado? ¿es un genio, ó un loco?"

Rubén Darío

Retrocedamos un poco en nuestra secuencia de eventos. Escasos dos meses después de la recién apertura de la Exposición Universal en la primavera de 1900, podemos ubicar al pianista en París, debido a la siguiente postilla carente de autor o título en Le fournal:

Le pianiste Gonzalo-Núñez a donné une audition de ses œuvres, dont le succès a été grand. La sonate en "la", l'Allegro de concert, "Loreley", et ses pittoresques "Danses cubaines" classent M. Gonzalo-Núñez au premier rang des maitres qui écrivent pour le piano. L'excellent pianiste s'est fait également applaudir en exécutant avec une rare virtuosité une rapsodie de Liszt, un nocturne, une valse et la polonaise en "mi" bémol de Chopin ("Gonzalo Núñez", 1900: 5). ${ }^{23}$

${ }^{22}$ Acta de matrimonio del 4 de enero de 1879, Manhattan. Su esposa, Trinidad Rodríguez, era natural de La Habana, Cuba. En calidad de profesor de piano y teoría ocupa varias posiciones en: New York Conservatory of Music (1880-1884), Scharwenka Conservatory (18911893), en su propia escuela Núñez Academy of Music (1893-1894), Grand Conservatory of Music of the University of the State of New York (1895-1896) y Eppinger Conservatory (1897-1898).

23 'El pianista Gonzalo-Núñez ofreció una audición de sus obras, cuyo éxito fue admirable. La Sonata en 'la', el Allegro de concierto, 'Loreley', y sus pintorescas 'Danzas cubanas' le otorgaron al Sr. Gonzalo-Núñez un puesto en la vanguardia de los primeros maestros que escriben para el piano. El excelente pianista fue también aplaudido por ejecutar con raro virtuosismo una rapsodia de Liszt, un nocturno, un vals y la polonesa en 'mi' bemol de Chopin”. 
Antes de trasladarse a Europa, Núñez había creado un nuevo sistema de notación musical, cuya recepción en la prensa fue variada y poco positiva. ${ }^{24}$ Este sistema, así como las teorías del compositor son referidas en una pequeña nota biográfica de Carlos Docteur en su Historia anecdótica de la música y de los grandes músicos, impresa por la Librería de la Viuda de Charles Bouret, la misma casa que publicó varias obras de Darío, entre ellas, la primera edición de Peregrinaciones en 1901 y la segunda y definitiva de Prosas profanas el mismo año. En dicha obra, Docteur apunta que el puertorriqueño:

según noticias, ha escrito una nueva, novísima, destinada a efectuar una revolución en el arte musical, especialmente en la Armonía y en la Composición, simplificándolas, presentando de tal modo su enseñanza, que una inteligencia mediana puede, en muy poco tiempo, conocer los secretos que, hasta ahora, sólo podrían penetrar, al cabo de muchos años de penosísimos esfuerzos, organizaciones sobresalientes. El divino arte debe de ser conocido de todo el mundo, por su influencia bienhechora en la educación y en la moral; y merece bien de la Humanidad quien con su talento, su laboriosidad y su honradez artística, reduce á lo más estricto necesario el cumplido estudio de la más bella conquista del alma humana (Docteur, 1901: 190).

La referida revolución está estrechamente relacionada con el tema del segundo texto dariano, su columna titulada "Cosas de Orfeo: Teología artística: Una nueva teoría musical", escrita el 25 de febrero de 1901 y publicada el 28 de abril en La Nación de Buenos Aires. Su contenido textual, a su vez, forma parte de un manuscrito que Núñez había compartido con sus amigos. Darío, en su preámbulo y antes de exponer las reglas musicales, relata que Núñez estuvo en Nueva York:

hasta que, por una especie de revelación mental - y aquí entra Swedenborg - concibió la idea de venir a París a publicar la buena nueva de sus Evangelios musicales. Llegó con muy buen pie. Su primera audición en el fournal fue coronada por el mejor éxito, pero al piano lo considera como cosa secundaria. Este admirable pianista abomina a los puros pianistas, y sobre todo, cosa terrible aquí, aborrece la moda! ¿Es un iluminado? ¿es un

${ }^{24} \mathrm{Al}$ parecer, en los artículos sobre el sistema de notación se empleó la información enviada por Núñez a los editores, pues muchas oraciones son idénticas: el primer artículo aparece sin título en Lewiston Evening Fournal (Maine, 29 de octubre de 1892, 3). El segundo, "Senor Gonzalo de J. Nunez [...] proposes a system of musical notation by which he contends that reading music may be considerably simplified". "Amusement", en Daily Inter-Ocean (Chicago, 30 de noviembre de 1891, 23). El tercero, "Piano Playing Made Easy. Senor Nunez Proposes a System of Musical Notation That Will Delight the Beginner", en New York Herald (23 de octubre de 1893, 11); este último contiene una ilustración musical del sistema. El cuarto, en una revista semanal habanera: "Un nuevo sistema de escritura musical", en El Fígaro (número X, 3 de junio de 1894, 19). Y, en el quinto, el editor de una revista religiosa, no identificado, comienza dando crédito al músico por su ingenio, para luego atacar el sistema, "Review. Response to Pamphlet Sent to Magazine. Music", en The Churchman (18 de marzo de 1893, 389). 
tocado? ¿es un genio, o un loco? Yo no entiendo de todos estos bemoles, pero ciertamente, no es un espíritu común, ni mucho menos, un fumista (Darío, 1977: 88).

Al igual que Darío, Nervo había señalado que el propio músico menospreciaba sus logros como pianista y compositor alcanzados antes de su revelación; asimismo, el poeta mexicano añadió información sobre el estado mental del nuevo amigo:

Y comenzó la explicación.

Aquel hombre había hecho la fusión más "bizarra" del mundo con la Biblia y la Música. Sabido es que los yanquis son furibundos exegetas. El "maestro Swedenborg", que, según parece, vivió luengos años en Nueva York, tornóse exegeta a su vez y de los más furibundos.

Empezó a buscar en la Biblia un sentido musical, y acabó por musicar hasta el Apocalipsis... en teoría, se entiende. El amor al símbolo llevóle a esas fronteras en que los videntes y los locos se dan la mano. Según él, la Virgen María, en el Nuevo Testamento, simbolizaba la música. Herodes simbolizaba el dinero.

$[\ldots]$

Al principio, el maestro intentó crear una nueva teoría musical; pero navegando en la Biblia, tornóse bíblico, vínole el afán incontrarrestable de interpretar, de hallar un símbolo en cada versículo, de desentrañar obscuridades, allí donde todo es abismo; y un día, creyéndose investido de poderes sobrenaturales, partió de Nueva York a París, donde, según decía, debía surgir la revelación futura y efectuarse la santa palingenesia de la verdad. Francia era la escogida por Dios para hacer brillar sobre el mundo la nueva luz (Nervo, 1967, t. 1: 1477).

Resulta evidente que Núñez conversaba con el dúo (o trío si incluimos a De Groux $^{25}$ ) desde una plataforma lingüística llena de vocablos esotéricos y de especula-

${ }^{25}$ De Groux fue durante años amigo íntimo de León Bloy, uno de los "raros" de Darío, el "verdugo de la literatura contemporánea"; pero, en 1898, comenzaron a distanciarse debido a sus actitudes diametralmente opuestas ante el asunto Dreyfus y con respecto a Zola, principal defensor público del militar condenado de manera injusta. Núñez, invitado a cenar por De Groux y su esposa, estuvo presente la dramática noche del 18 al 19 de junio de 1900, cuando De Groux, en un acceso de paranoia, expulsó a la familia Bloy de su apartamento en el boulevard de Port-Royal (Bloy, 2000: 876). Núñez, a su vez, fue quien presentó a De Groux con Darío y Nervo. En una crónica redactada en 1909, Darío recuerda al "pintor Henry de Groux, loco o genio; el cual nos fue presentado por otro personaje prodigioso, músico y ocultista, que tenía unas hijas encantadoras y nos leía unos alucinantes comentarios del Apocalipsis" (Darío, 1909: 5; Darío, 1912: 70). Sobre la vida de De Groux, los rasgos característicos de su pintura y los motivos de la identificación de Darío con él, véase Parrondo (2017). En relación con las personalidades y la interacción entre Darío, Nervo, De Groux y Núñez, véase Hernández (2006). Resulta una pena que los cuatro personajes no lograran integrar a León Bloy a su pequeña red artístico-esotérica. Bloy fue un gran escritor, aunque ignorado y mal interpretado en su época, y el "cuarteto parisino" hubiera ganado mucho al convertirse en quinteto. 
ciones innovadoras. Es, en definitiva, esta visión la que se manifiesta en el manuscrito El Arcano musical, según Darío, ${ }^{26}$ de donde emanan tales disertaciones dogmáticas y aseveraciones bizarras: producto de un espíritu arraigado en lo místico, lo moral y, por supuesto, en las doctrinas swedenborgianas y en el pensamiento católico simbolista. A modo de advertencia, ante su intención de presentar esas nuevas teorías o a manera de excusa y distanciamiento de la veracidad de las mismas, Darío escribe: "Yo no entiendo de todos estos bemoles", y añade:

Me leí varias páginas de sus comentarios, ó más bien, de sus exégesis de los Evangelios, de que ya me había hablado en la iglesia swedenborgiana. Encuentro que hay pasajes que no comprendo, pasajes que se me antojan caprichosos, pasajes vulgares y pasajes sublimes. "No soy un escritor, me dice, mi obra no pertenece a la literatura". En verdad le replico, me parece usted un teólogo. Este libro, Arcano musical, es una obra de ideología artística (Darío, 1977: 88-89).

Pero, nuevamente, en lugar de proseguir y presentarnos las reglas, Darío dilata su narración añadiendo una improvisada escena musical y unos versos de un amigo médico:

Había oído hablar de su Lorelay, una composición poémica, una composición legendaria, llena de ensueño y de encanto. Y la oí en seguida, ciertamente deliciosa evocación, paisaje misterioso en que se mueve la fatal y poética figura de la creación germánica. Una noche, después de oír esta bella y sutil música, escribió Marcel Réja ${ }^{27}$ el prologuista del Inferno ${ }^{28}$ del escandinavo Strindberg - los siguientes versos, hasta hoy inéditos:

Irrésistible, avec sa voix comme un cristal,

En son domaine fabuleux

De flots berceurs, de reflets bleus,

Son âme pure enclose aux brumes virginales

Mystérieuse avec ses appels capitaux

Son buccin d'or chantant selon tels sortilèges,

${ }^{26}$ Existe una discrepancia en este título, pues su autor bien pudo cambiarlo posteriormente, debido a que el manuscrito existente lleva por nombre: Los arcanos de la música. Nótese, además, que adjunto al manuscrito se encuentra la introducción mecanografiada, en inglés, donde aparece el título "Musical Arcana".

${ }^{27}$ Marcel Réja es el pseudónimo de Paul Meunier (1873-1957), doctor en medicina (París, 1900) y psiquiatra francés ligado al arte marginal (l'art brut). Fue, asimismo, poeta, dramaturgo y novelista, que escribió sobre los sueños (Les Rêves et leur interprétation o Los sueños y su interpretación) y el arte de sus pacientes enfermos mentales (Couet, 2016).

${ }^{28}$ Inferno es una novela autobiográfica del escritor sueco August Strindberg, publicada en 1897. Narra la residencia del autor en París, donde, lejos de su familia y amigos quedados en Estocolmo, se dedica al estudio obsesivo de la alquimia, el ocultismo y el swedenborgianismo. 


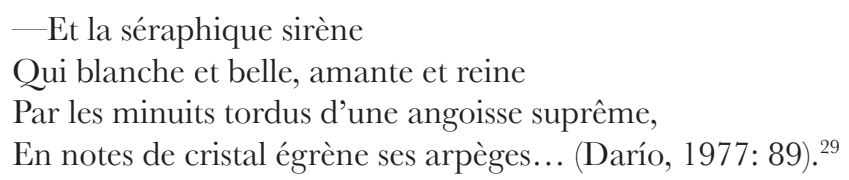

Las nuevas leyes o reglas armónicas, que serán el tema principal de "Cosas de Orfeo", provienen de la sección "Armonía práctica y contrapunto" en el manuscrito de Núñez, Los arcanos de la música (Núñez, s. f.: 21-65). Después de una advertencia al lector, de no emitir juicio alguno antes de leer y estudiarlas todas, Núñez enuncia su definición swedenborgiana de esta ciencia: "Armonía, quiero decir, la resultante de una serie de leyes dadas por Dios para conservar y sostener todo lo creado. Es la ley del amor puesta en práctica" (Núñez, s. f.: 22). Debemos, además, añadir que tanto las composiciones musicales de Núñez como la teoría presentada en esta obra son fundadas en el sistema tonal modal de la música que estudió con Savard en el conservatorio parisino, y no en lo que se llamará más tarde la modalidad europea atonal o dodecafónica. ${ }^{30}$ La armonía que utiliza se basa en el sistema tonal mayor-menor perteneciente a los denominados periodos clásico y romántico, pero con matices colindantes con el periodo modernista. ${ }^{31}$

Prosigamos con una breve exploración y contraposición de los dos textos particulares de la teoría. A primer vistazo, el tratado nos muestra una discrepancia en contenido y secuencia con respecto al artículo periodístico, pero esto no nos sorprende, porque el tratado exige una exposición confeccionada y mucho más detallada. En contraposición, en el artículo dariano tanto la enumeración como las ilustraciones musicales son directas, sucintas y mucho menos elaboradas.

De las doce reglas, las cuatro primeras y la última se presentan de forma casi idéntica, mientras que las restantes se distancian unas de otras, lo cual resulta lógico si aceptamos que los propósitos de sus autores son distintos: en el caso de Darío, ofrecer un contenido complejo de modo sucinto y liviano a los lectores bonaerenses no necesariamente versados en teorías musicales; en el caso de Núñez, compartir una

29 "Irresistible, con su voz como un cristal,/ En su fabuloso dominio/ De olas oscilantes, de reflejos azules, / Su alma pura es encarcelada en las nieblas virginales/ Misterioso con sus apelaciones embriagantes/ Su dorado silbido cantando como hechizos, / - Y la sirena seráfica/ Que blanca y hermosa, amante y reina/ Por las mediasnoches torcidas de una angustia suprema,/ En notas de cristal depura sus arpegios...". Estos son los primeros diez versos de unos 36 incluidos en "Cosas de Orfeo".

${ }^{30}$ Ver su Mazurka para piano (Núñez, 1891).

${ }^{31}$ El dodecafonismo es una manifestación de la música atonal, donde las mismas doce notas de la escala cromática son tratadas como equivalentes y, a su vez, sujetas a una relación ordenada que no establece jerarquía tonal mayor-menor entre las notas. Dicha técnica, inicialmente, fue utilizada por el método creado por Arnold Schoenberg y sus discípulos en 1921. 
revelación muy personal, elaborar una nueva teoría, con el fin de persuadir tanto al estudiante como al músico profesional a que acepten y utilicen un nuevo sistema.

Las discrepancias comienzan con la Regla IV, a la que se alude en "Cosas de Orfeo" de Darío: "Dos voces disonantes, deben formar consonancia en el acorde que sigue. Su movimiento no es obligado. Es ad libitum ${ }^{32}$ al grado de la escala que quiera ir. Cualquiera de las dos puede resolverse en consonancia con la otra" (Darío, 1977: 92).

En Arcanos, Núñez indica: "Cuando dos notas forman disonancias, deben separarse para formar consonancia, sea que estén solas, sea que estén acompañadas por otras" (Núñez, s. f.: 25). Nótese que, en la primera versión, el canon contiene un vocablo que estimula a seguir la regla de manera opcional (movimiento no obligado, ad libitum, puede resolverse), mientras que la segunda es más breve, exacta, exigente y rígida (deben separarse).

$\mathrm{Al}$ comienzo de "Cosas de Orfeo", Darío había expresado a sus lectores que en su conversación con el músico amigo le había advertido: "hablaré en La Nación de sus ideas y que pediré la opinión de autoridades como nuestro Frexas y mis amigos Williams, Aguirre y Berutti”. ${ }^{33}$ De estos expertos músicos, el maestro Julián Aguirre responde al llamado de Darío el 22 de mayo:

$\mathrm{Al}$ ver en un ejemplar de La Nación del mes pasado, ejemplos de intervalos y acordes, busqué la firma atribuyendo el trabajo a alguno de nuestros maestros conocidos, y ¡cuál no sería mi sorpresa al ver el nombre de Rubén Darío!

El poeta exquisito; el prosista novedoso y original tiene también sus perfiles de músico. ¡Qué verdadero poeta no los tiene! y ha demostrado su preocupación y su entusiasmo en sus correspondencias sobre los Maestros Cantores de Nuremburg [sic]; pero de ahí a desentrañar y analizar acordes hay un largo trecho, pensaba yo al comenzar el artículo.

En éste, Rubén Darío se ciñe a exponer una teoría de un amigo, portorriqueño [sic], adepto de Swedenborg y reformador de la ciencia musical.

\footnotetext{
${ }^{32}$ En el caso específico de la música, se usa el término ad libitum o su abreviación ad lib para indicar que cierto pasaje musical está a discreción del intérprete, es decir, se puede improvisar o elaborar a gusto.

${ }^{33}$ Enrique Frexas de Sabater (1847-1905), poeta, compositor y dramaturgo español, fue crítico de La Nación en la última década del siglo xix; Alberto Williams (1862-1952), compositor, pedagogo y pianista bonaerense. Al igual que Núñez, estudia con Mathias en el Conservatorio de París; a su regreso a Argentina, fundó el Conservatorio de Música. Autor de obras estéticas y didácticas, así como compositor prolífico que utilizó el folklore argentino. Julián Aguirre (1868-1924), compositor y pedagogo argentino, estudió en el Conservatorio Real de Madrid y en París. Fundó la sección de la música del Ateneo y la Escuela Argentina de Música en 1916, iniciando el nacionalismo en la música de su país, y sintetizó el folklore argentino en la música culta. Arturo Berutti (1858-1938), compositor sanjuanino, estudió en el Conservatorio de Leipzig en 1884, y luego en París y Milán. Tradujo el tratado de armonía de su maestro alemán Salomón Jadassohn.
} 
La reforma es radical, y para llevarla a cabo, el autor reduce todas las reglas a doce que enumera y expone a modo de axiomas.

Algunos de estos son originales, otros muy discutibles. En general yo creo que toda reforma o revolución se hace por las obras y no por las teorías, y que si en el conocimiento se va siempre de lo simple a lo complejo, las simplificaciones tienen una utilidad más aparente que efectiva. Creo que vale más un ejemplo que cien doctrinas (Aguirre, 1901: 4).

En términos generales y como pedagogo, Aguirre duda del valor práctico de estos axiomas, pero, a su vez, afirma sobre las reglas del autor: "Estoy conforme con el tratadista en lo que dice respecto de la igualdad de sostenidos ascendentes y bemoles descendentes $[\ldots]$ como también me parecen excelentes los consejos que se refieren a movimientos de las voces...". La exposición y el análisis en respuesta al texto de Darío se presentan de manera clara y directa. En general, Aguirre duda de la veracidad y del pragmatismo de los axiomas, y difiere de la visión negativa del tratadista ante la creación de las obras musicales del momento:

Por último, habla el autor en sus consideraciones generales, de promover con su tratado un renacimiento que acabe con la "amargura, la crisis y el estado deplorable en que se encuentra la música actualmente" y también disiento en esto de su opinión. SaintSaëns, Massenet, Brahms, Max Bruch, Puccini, Franchetti, Franck, Grieg y otros cien, son prueba del estado floreciente de la música en nuestro tiempo, y conjuntamente la demostración más palpable de la eficacia del estudio detenido y completo, que al amigo del queridísimo Rubén Darío, se le antoje laberíntico y confuso (Aguirre, 1901: 4).

En una tarde opaca del otoño de 1901, Darío visita a Núñez para saber su opinión sobre los milagros de Lourdes. "Le encontré en medio de su familia, y en unión de su inseparable Henry de Groux. Una gran Biblia estaba abierta en una mesa", recuerda el poeta (Darío, 2000: 174). Como resultado de aquel encuentro, Darío redactó una crónica que cierra el primer libro de La caravana pasa, la cual consiste en un largo discurso de Núñez, quien demuestra de manera contundente que los milagros de Lourdes son obra del demonio. Darío no responde ni una sola palabra. ${ }^{34}$ Desde el punto de vista filológico, no se ha podido aclarar todavía si ese texto tan largo, con citas apocalípticas y referencias a artículos de prensa (Darío, 2000: 171-198), es realmente un monólogo de Núñez, reproducido por Darío gracias a su prodigiosa memoria, o si se trata de otro manuscrito, hoy perdido, que el arcano compositor facilitó al poeta. Han de pasar dos años antes de que surja entre ambos un nuevo acontecimiento documentado.

${ }^{34}$ A pesar de que varios intérpretes han tratado de estilizarlo como devoto a la virgen de Lourdes (véase Schmigalle, 2016). 


\section{Pianos y pianistas}

Domingo 7. 3. 1903. $85 \mathrm{~B}^{\mathrm{ard}}$ de $\mathrm{P}^{\mathrm{t}}$ Royal

Querido amigo

Por este mismo correo le envío un trabajito sobre pianos y pianistas que tal vez pueda servirle. Si le parece demasiado duro en alguna parte, recorte como le plazca, no olvidando que esos mercaderes del templo, merecen todos ser azotados. Recibí su carta y aunque lo siento, no le esperamos hoy.

De V. affmo.

Núñez (Núñez, 1903a).

Al dorso de esta tarjeta de visita, encontramos:

Gonzalo Nuñez,

Pianiste et Compositeur,

Ex-premier prof- au Conservatoire de New York N. . . C. of Music

Professeur de Piano à l'Externat de l'Assomption à Paris ${ }^{35}$

85 Boulev ${ }^{d}$ de Port-Royal (Núñez, 1903a).

El trabajito sobre pianos y pianistas, enviado junto al paquete dirigido al poeta nicaragüense, comprenderá, en particular, la sección "La decadencia del piano y el arte de ejecutarlo", inserta en otra sección del manuscrito (Núñez, s. f.: 281-287), que eventualmente se convertirá en el artículo "Pianos y pianistas", fechado en mayo de 1903 ( $\mathrm{La}$ Nación, 4 de junio de 1903). Nos resume Schmigalle en su introducción que el escrito trata "sobre la decadencia en el arte de tocar el piano, la influencia nefasta de los fabricantes yanquis, y la resistencia del público francés contra la transformación del pianista en un acróbata" (Darío, 2006: 18).

En este momento, ambos colegas se encuentran nuevamente ante una favorable coyuntura: el músico se aprovecha de otra oportunidad de esparcir su pensamiento y filosofía musical a través de su amigo, corresponsal del periódico hispano de mayor alcance en el mundo (Ramírez, 2012: 86), al enviarle su escrito; a su vez, Darío, como en tantas de sus crónicas y entrevistas bonaerenses, utiliza un modelo recurrente en su obra: platicar sobre algún argumento de interés mutuo con amigos conocidos, verterlos en sus obligados artículos como corresponsal y transmitirlos, inmediatamente, a Buenos Aires. ${ }^{36}$

${ }^{35}$ El Instituto Externo de la Asunción es un colegio privado, hoy llamado L'Institut de l'Assomption-Lübeck, creado en 1882 y ubicado en 6 Rue de Lübeck, distrito 16 de París, a seis kilómetros de distancia de la residencia del compositor en el boulevard de Port-Royal.

${ }^{36} \mathrm{Al}$ respecto, Schmigalle apunta: "Otro subgénero de dentro del variadísimo género de la crónica es la entrevista. Darío tuvo el arte de encontrar expertos y, también, conocedores sobre los temas más variados, sabe hacerlos hablar y escucharlos activamente" (Schmigalle en Darío, 2006: 16). 
Debo aclarar que no se ha podido constatar que el manuscrito enviado por Núñez al poeta, en esa ocasión, sea idéntico al que podemos estudiar hoy día en el Archivo General de Puerto Rico, ni cuál es anterior a priori. ${ }^{37}$ Pero podemos inferir que el poeta, al recibirlo, lo leyó, luego lo discutió con su amigo, lo revisó y lo incluyó en la columna de La Nación.

Comenzamos un análisis de ambos escritos:

Salgo de una audición del admirable pianista Raoul Pugno. ${ }^{38}$ La influencia armoniosa persiste [...] flota como un eco de lo que acabo de escuchar. Converso con el maestro Núñez, otro admirable pianista, y le manifiesto cómo ese instrumento tan abominado de los vecinos tiene poetas que lo celebran - aunque también poetas que lo han maldecido y burlado (Darío, 2006: 261).

Así inicia el artículo de Darío, pero, antes de intercalar el texto de Núñez, ofrece un preludio (Darío, 2006: 261-265), para luego introducirnos al músico: “Qué dice? ¿Qué dice usted maestro? ¿Qué dice su autoridad en la materia? Núñez se detuvo, irguió su gran figura. Igual a Balzac [...] y me contestó: El juicio mío no es igual al de usted, poeta amigo, ni al de otros poetas. Escuche tengo un recuerdo" (Darío, 2006: 266-267). Es aquí, en este punto, donde Darío retoma lo referido en el manuscrito del pianista:

El domingo 23 de noviembre de 1902, en el Concierto de Lamoreaux, ${ }^{39}$ hubo un tumulto inesperado debido a la primera presentación en París de la artista americana Mme. B. F. Z.. ${ }^{40}$ pianista que a juzgar por la opinión de los expertos, es dueña de una muy rara habilidad.

${ }^{37}$ La única fecha citada dentro del escrito aparece en tres ocasiones cuando el autor inserta 1903 entre paréntesis: "en estos tiempos" (Núñez, s. f.: 132); "Poco le falta hoy para lograrlo" (Núñez, s. f.: 211); y directamente en "Estamos en el año 1903" (Núñez, s. f.: 279). Pero no podemos asegurar la fecha de compleción del mismo.

${ }^{38}$ Hubo varias oportunidades para escuchar a Raoul Pugno en París en esas fechas. Darío y Núñez asistieron probablemente a una de las audiciones de sonatas antiguas y modernas, ejecutadas por Eugène Ysaÿe y Raoul Pugno, el séptimo año consecutivo, en la sala Pleyel, 22 rue Rochechouart, dedicadas ese año exclusivamente a Bach y Beethoven, el 13, 15, 18 y 20 de mayo (Le Figaro, 13 de mayo de 1903).

${ }^{39}$ Otro nombre dado a la serie de conciertos de la Société des Nouveaux-Concerts creadas por el difunto director francés de ese apellido, ahora dirigida por su yerno Chevillard.

${ }^{40} \mathrm{El}$ texto de Núñez no identifica a la pianista por su nombre, sólo por su sexo e iniciales "Mme. B. F. Z" (en lugar del orden correcto "F. B. Z."); Darío es más explícito y se refiere a ella por su nombre y apellidos, ninguno de los dos asistió al concierto. La pianista interpretó el Concierto no. 4 de Saint-Saëns, y su colega Moritz Moszkowski le había prevenido de posibles demostraciones de desaprobación. Antes de hacer su entrada en escena, alguien gritó desde el balcón "Pas de piano" ("Piano, no") y otro "Ce n'est pas musique" ("Esto no es música"), al finalizar triunfó, pues el público la reclamó cuatro veces (Macleod, 2015: 99-100). 
Según las noticias que tenemos, al presentarse dicha Señora se levantó el público, o parte de los concurrentes, protestando ${ }^{41}$ contra la presencia de solistas de piano en conciertos puramente sinfónicos y manifestando su repugnancia por tener que contemplar forzosamente los Tours de force y giros acrobáticos de los ejecutantes modernos que sólo invaden esas fiestas musicales para hacer gala de su espantosa fuerza y fenomenal ejecución. Eso es lo que se dice.

Sin tratar de justificar en manera alguna a los iniciadores del escándalo, no podemos dejar de ver en lo ocurrido una consecuencia inevitable de males que tienen su raíz muy profunda, y que solamente puede desaparecer cortando el abuso y poniendo de manifiesto el error de los unos y de los otros. Como esos escándalos se siguen produciendo y se producen cada vez que aparece un pianista nuevo, ${ }^{42}$ necesario es creer que no obedecen a odios personales, y que son efecto de una evolución cuyas causas estudiaremos.

¡En el mundo musical chocan hoy intereses tan opuestos, y es tan difícil hacer resonar la voz de la Verdad! (Núñez, s. f.: 281). ${ }^{43}$

Este argumento, el estado actual del ambiente musical parisino y el futuro de su manifestación artística, que para algunos lectores puede considerarse más bien como asunto inconsecuente, en otros logra despertar una conmoción, entre amantes de la música, fanáticos conservadores y liberales, críticos, compositores, intérpretes, editores, hasta agentes de la ley y abogados. Al respecto de esta discusión, el escritor francés Romain Rolland señaló en 1903: "la grande question du mois musical est ce que je nommerai la guerre des concertos [sic]" (Rolland, 1903:12). ${ }^{44}$ Batalla que se manifestó por primera vez en la prensa en 1902, y se prolongó hasta 1904. Entre los renombrados músicos involucrados en la guerra, se encontraban Saint-Saëns, Dukas, V. d'Indy, Fauré y Paderewski.

¿Cuál fue el incidente que había iniciado tal hostilidad? En la tarde del 16 de febrero de 1902, cuando en la sala de conciertos del Théâtre du Châtelet se interpretaba el Concierto para violin en mi menor de Luigi Spohr, inesperadamente "Willy Burmester est contraint de se retirer sous le huées après l'exécution du premier mouvement" (Sérié, 2015: 301). ${ }^{45}$ A pesar de que el incidente ocurre en febrero de 1902, no es hasta octubre del mismo año cuando comienza el debate público en la prensa, y resulta muy probable que dichas manifestaciones no esquivaron a nuestro dúo.

Seguimos con la secuela en el tratado de Núñez:

${ }^{41}$ En el texto de Darío: "protestando a gritos".

${ }^{42}$ Durante esta contienda, en realidad no se discriminaba por el instrumento, los fustigadores rechazaban cualquier solista que se presentaba en una velada musical ante una orquesta.

${ }^{43}$ El tercer párrafo citado es idéntico al de Darío, pero la última oración ha sido eliminada.

44 "la gran cuestión musical del mes la llamaré la guerra de los conciertos".

45 "el Sr. Willy Burmester se vio obligado a retirarse bajo los abucheos al acabar de interpretar el primer movimiento". 
Los compositores modernos no tienen hoy aquella discreción. Desde Schumann hasta la fecha se escribe con el objeto de establecer una lucha, un pugilato entre el piano y la orquesta. De ahí procede la decadencia en el arte de tocar el piano ${ }^{46}$ y asimismo la degeneración y decadencia de los instrumentos que construyen en nuestros días. Lejos estoy de negar los méritos musicales de algunas de las composiciones de esa clase que se oyen hoy, pero hay que reconocer con dolor, que se han despertado en los pianistas ideales de otro género que lícitamente pueden exigir de un piano y de un solista (Núñez, s. f.: 282).

La noción de un pasado idóneo y dorado de la época Romántica de la civilización occidental, persistente en el pensamiento de artistas de la Belle Epoque, es afín a las ideas de Darío y Núñez. Pero recordemos que, al tiempo en que se producen los dos escritos, ambos autores, y más en el caso específico de Darío, quien siempre mantenía informados a sus lectores del Cono Sur de la última moda parisina, ignoraban que sus textos eventualmente los convertirían en protagonistas de la mencionada contienda musical. Prosiguiendo con el manuscrito:

De manera que menospreciando los encantos naturales de ese bellísimo ${ }^{47}$ instrumento, los ejecutantes en sus sueños de gloria no ven sino el día de romper con todo; no conciben sino bravura; el supremo ideal del pianista moderno, hay que buscarlo en la escena de Don Quijote repartiendo mandobles y tajos sobre el retablo de maese Pedro. Empresa inútil. Lo que han traído es el cansancio y el desdén por la parte del público, como estamos viendo hoy. ${ }^{48}$ Se les considera como acróbatas que vienen a perturbar las emociones que la verdadera música despierta. Se les ha hecho descender al nivel intelectual de los bailadores de cuerda floja y los tragadores de vidrio y fuego. ${ }^{49}$ Podrá ser injusta y exagerada por parte del público de nuestros días, ${ }^{50}$ pero es indiscutible el hecho de que el piano moderno no tiene los encantos que fueron revelados por Chopin, Thalberg, Liszt y otros. Aquellos hombres veían en el piano una orquesta en miniatura (Núñez, s. f.: 282-283). ${ }^{51}$

${ }^{46}$ Darío apunta: "Hace más de cuarenta años que el célebre Héctor Berlioz predijo la decadencia del arte del piano" (Darío, 2006: 268); la cita no se ha podido identificar en la obra del compositor francés.

${ }^{47}$ Darío elimina el adjetivo y simplemente escribe "de ese instrumento" (Darío, 2006: 269).

${ }^{48}$ En Darío, "que estamos viendo ahora" (Darío, 2006: 269).

${ }^{49}$ Darío añade: "de cuerda floja y de aissaouas, tragadores de vidrio y fuego" (Darío, 2006: 269). En la edición crítica del artículo, nota 496, encontramos: "Los aïssouas o aïssauas son una secta de fanáticos mahometanos [...] los cuales para demostrar que en sus religiosos éxtasis son insensibles á todo dolor [...] se pinchan con toda clase de armas é instrumentos las mejillas, lengua, brazos y mascan brasas de fuego" (Darío, 2006: 269).

${ }^{50}$ Esta oración ha sido dividida en dos partes. La primera parte, en el texto de Darío, comienza: “¿Algo de exageración artística, maestro? Algo de exageración quizá, en el público, es una manera de apreciar los esfuerzos, pero" (Darío, 2006: 270); la continuación es idéntica al escrito de Núñez.

${ }^{51}$ En su época, los tres pianistas-compositores causaron gran admiración por su ejecución e innovaciones en la técnica y en sus obras para piano. 


\section{Núñez, Darío y el manuscrito Los arcanos de la música}

Nuevamente de manera ingenua e ingeniosa, Darío enlaza los dos textos con otra pregunta: “¿Y usted cree en lo de la orquesta en miniatura?” (Darío, 2006: 271). Y, después, inserta el escrito de Núñez quasi verbatim:

Nosotros no solamente creemos que el piano es una orquesta en miniatura, sino que le aventaja en ciertos efectos que la Verdadera orquesta no puede producir. ${ }^{52}$ Pero en cambio, la fuerza sonora y la riqueza de los diferentes timbres producen efectos casi imposibles en el piano.

Es pues, insensato, pretender que un reloj de bolsillo de timbres dé los timbres de un reloj de Iglesia. ${ }^{53}$ Pero no por eso puede afirmarse que no sea admirable (Núñez, s. f.: 284). ${ }^{54}$

Recordamos que, en su tarjeta de visita enviada al poeta, Núñez le sugirió: "Si le parece demasiado duro en alguna parte, recorte como le plazca" (Núñez, 1903a). La comparación de los textos de ambos autores demuestra que, efectivamente, Darío suprimió y cambió muy poco:

Los encantos y delicadeza del piano se han olvidado casi por completo. Es un arte que pertenece a la historia, y eso para dar lugar a una manifestación violenta e ingrata, traída por la locura de ciertos artistas y por el comercio de los fabricantes de piano. ${ }^{55}$

En los últimos treinta años, ${ }^{56}$ la fabricación de pianos ha tomado proporciones tales, que según datos recientes los Estados Unidos de América fabrican ellos solos más pianos que toda Europa juntos. ${ }^{57}$

Esta crecidísima producción de instrumentos ha traído como resultado inevitable una rivalidad desordenada e indecorosa, en la cual cada fabricante se esfuerza en justificar los méritos de su casa arrebatando firmas, recomendaciones, por todos los medios que están a su alcance. ${ }^{58}$ Regalan instrumentos ${ }^{59}$ a ministros, artistas, Generales, obispos, ${ }^{60}$ Reyes

${ }^{52}$ Darío modifica la oración: "No solamente creo que el piano es una orquesta en miniatura, sino que aventaja á la orquesta en ciertos efectos que ésta no puede jamás producir" (Darío, 2006: 271).

${ }^{53}$ Darío añade a esta oración signos de exclamación (Darío, 2006: 271), que no aparecen en Núñez.

${ }^{54}$ Reproducimos este fragmento del texto de Darío: "No solamente creo que el piano es una orquesta en miniatura, sino que aventaja á la orquesta en ciertos efectos que ésta no puede jamás producir. Pero en cambio, la fuerza sonora y la riqueza de los diferentes timbres producen efectos casi imposibles en el piano".

${ }^{55}$ Hasta este punto, los escritos se han presentado de forma paralela y son idénticos (Núñez, s. f.: 284-285; Darío, 2006: 271).

${ }^{56}$ Darío inserta "-Escuche." (Darío, 2006: 271), y enlaza con "En los últimos..."

${ }^{57}$ Darío: “toda Europa junta” (Darío, 2006: 272).

${ }^{58}$ Darío termina la oración: "medios que sirven a su 'réclame" (Darío, 2006: 272).

${ }^{59}$ Darío sustituye la palabra "instrumentos" por "mesas de armonía” (Darío, 2006: 272).

${ }^{60}$ Darío omite a los obispos del grupo (Darío, 2006: 272). 
y Emperadores, para decir en sus circulares y anuncios que aquellas personalidades son admiradoras de sus instrumentos. ${ }^{61}$ París se halla hoy muy amenazada por esa nube de langostas destructoras ${ }^{62}$ del arte. Los fabricantes americanos ${ }^{63}$ hacen todos los esfuerzos posibles para conseguir a toda costa el mercado de esta ciudad reina, porque saben que si París se diera en su favor, han conquistado el mundo entero (Núñez, s. f.: 285).

Nótese que nuestro músico se mantenía bien informado sobre la fabricación de su instrumento musical favorito. Durante las décadas de 1890 a 1910, las estadísticas anuales eran encabezadas por las manufacturas inglesa, francesa, prusiana y norteamericana, lo que las colocaba a la delantera en el mercado mundial. En comparación con los países mencionados en los escritos de Núñez y de Darío, se estima que para 1890 se produjeron 20000 instrumentos en Francia mientras que 72000 se produjeron en los Estados Unidos; para la producción mundial del año 1910, Estados Unidos sobrepasará a todos con unos 370000 pianos, en contraposición con los franceses que disminuyeron a unos 25000 (Vogel, s. f.). Ahora bien, continuando con el ensayo de Núñez:

Y digo esto, porque los pianistas son hoy esclavos. No pueden vivir sino por la protección que les dispensan las casas de piano [...] Buscan para el objeto los pianistas más estrepitosos, y a fuerza de alabanzas preparadas de antemano, anuncios, cartelones extravagantes, retratos, y otros medios ajenos á la verdad artística, ${ }^{64}$ introducen al pianista o la pianista que cuando se sienta al piano, llega precedido del respeto que inspira un León ú otra fiera espantosa. ${ }^{65}$ $\mathrm{El}$ artista, por su parte, tampoco desdeña la ocasión de hacerse pasar por un fenómeno, o un ser del otro mundo, y en virtud de la larga enredada cabellera, y sus ${ }^{66}$ movimientos de fiera embravecida, arranca los aplausos que comparten su virtuosidad y su extravagancia.

Más fácil es tocar acompañado que solo. El pianista que se imagina estar en un grado de superioridad porque ha ejecutado un concierto estrepitoso acompañado por la orques-

${ }^{61}$ El propio Núñez había sido víctima de esta costumbre que persiste hasta el día de hoy; se puede documentar su nombre entre los artistas incluidos en anuncios de las compañías de piano. "I have been playing the Behr pianos publicly and privately for the past two years and fell happy to acknowledge they possess the very highest qualities of touch and tone. I do not desire to play a better instrument than yours". Firmado Gonzalo Núñez, en "Celebrated Pianists of Modern Times. A few words from them endorsing the great Behr Bros. Pianos" (The Roanoke Daily Times, 20 de septiembre de 1896: 1E).

${ }^{62}$ Darío sustituye la frase "esa nube de langostas destructoras del arte" por "esa nube destructora del arte" (Darío, 2006: 272).

${ }^{63}$ Darío sustituye "americanos" por "yanquis" (Darío, 2006: 272).

${ }^{64}$ Darío: "á la verdad del arte" (Darío, 2006: 273).

${ }^{65}$ Darío sustituye "un León ú otra fiera espantosa" por "un león, un elefante...” (Darío, 2006: 272).

${ }^{66}$ Darío sustituye "la larga enredada cabellera, y sus..." por "la larga cabellera, y movimientos..." (Darío, 2006: 273). 
ta, se engaña tristemente, porque el verdadero artista del piano, no es el que toca en uno u otro lugar, sino el que solo, con su arte, domina a su auditorio sin cansarlo durante dos o tres horas.

Para obtener ese resultado, ahí están los salones de concierto que abundan en París. En ellos pueden los pianistas presentarse con la dignidad é independencia que les corresponde y los pianos serán juzgados con arreglo á las exigencias del arte verdadero (Núñez, s. f.: 286-287). ${ }^{67}$

Aquí finaliza el escrito de Núñez, mientras que Darío aprovecha y, a manera de breve epílogo, apostilla unas pocas líneas como en una escena de teatro: haciendo entrada con su amigo al jardín de Luxemburgo, se encuentran con un pequeño monumento erigido al poeta del piano Chopin. Concluyendo Darío:

El busto se alzaba en el crepúsculo, sobre la musa que surge del bloque sustentante.

- He ahí, me dijo el maestro, uno que fué grande, sin melena de león ni manotadas de tigre. Ese fué sin pecado.

- Tuvo uno muy grande, le dije.

?

- George Sand (Darío, 2006: 273-274) ${ }^{68}$

Durante este tiempo, Darío y Núñez, pues Amado Nervo se había marchado a México en 1902 y Henry de Groux se encontraba camino a Florencia, siguen confiriendo sobre temas artístico-místico-religiosos. Escasas siete semanas posteriores a la fecha del envío del trabajïto, Núñez, que posiblemente continuaba revisando su tratado envuelto en exégesis, remite con apremio la siguiente postal:

Miércoles.

Querido amigo Darío

Me interesa muchísimo saber en qué versículos de la Biblia se encuentra el siguiente pensamiento:

"A tu amigo melancólico dale cerveza

y a tu amigo triste dale vino"

ó vice versa.

Búsquelo y dígame y le saluda,

Su amg.

Núñez (Núñez, 1903b).

${ }^{67}$ Estos dos últimos párrafos son idénticos.

${ }^{68}$ El tema de la relación sádico-masoquista entre George Sand y Chopin fue una obsesión de Darío. Lo trata, mucho más tarde, en sus dos novelas fragmentarias En la isla de oro y El oro de Mallorca (Darío, 2017: 311-320 y 371-380, respectivamente). El "pecado muy grande" de Chopin fue, según Darío, el haberse sometido, por amor o por debilidad de carácter, al maltrato de la ambiciosa y fría escritora francesa. 
Darío era un gran conocedor de la Biblia, ${ }^{69}$ y Núñez lo sabía, como recordará Osvaldo Bazil: "[La Biblia] era casi su libro único y su lectura constante en muchos años. En todos los países donde llegaba adquiría un ejemplar de la Biblia. Exigía que fuera con el texto en latín con la traducción española al frente. Él no hablaba ni leía latín pero lo entendía un poco y le gustaba citar el texto en latín en sus escritos" (Bazil, citado en Meléndez: 153). Por eso es probable que Darío supiera contestar la consulta de su amigo, recordando Los sacros libros del Viejo y Nuevo Testamento traducidos por Casiodoro de Reina en 1569, donde el versículo 31: 6 de Los Proverbios de Salomón reza: "Dad la cerveza al que perece, y el vino a los de amargo ánimo". ¿Y por qué a Núñez le interesaba tanto localizar esta referencia? Podemos formular una hipótesis. Seis años antes, en 1897, Émile Durkheim había publicado su famoso libro sobre el suicidio, en el cual afirma que una sociedad entera puede estar mentalmente enferma; asimismo, mide la patología de las sociedades con base en estadísticas que documentan el grado de alcoholismo, los internamientos en clínicas psiquiátricas y los suicidios. En un país donde se banalizaba el consumo del licor ("le vin n'est pas un alcool" $)^{70}$ y se asociaba el alcohol con la alegría de vivir, esas investigaciones chocaron. Tal vez Núñez quiso demostrar que la relación establecida por Durkheim entre el alcohol, el sufrimiento y la muerte no fue completamente novedosa, sino que tenía antecedentes antiguos y hasta bíblicos. Aunque alejándose de las intenciones de Durkheim, sus análisis, al igual que otros aspectos de la vida finisecular, se podían interpretar como un ejemplo del "temor ante el fin de los tiempos y el anhelo de redención mediante la llegada de Cristo" (Parrondo, 2017: 141).

\section{Coda}

Hasta aquí encontramos documentada la relación entre nuestros personajes, y asumimos que prosiguieron sus extendidas pláticas ante la Biblia abierta sobre la mesa, después de una velada al piano frente al cuadro de Henri de Groux en la sala de la familia Núñez, obra del amigo raro que los había presentado hacía ya un tiempo; pero, paulatinamente, sus caminos comienzan a separarse.

Núñez regresa a sus faenas cotidianas, como concertista y pedagogo, ofrece varios recitales en Londres, donde publicó varias piezas para piano (1904), luego en La Habana (1905) y Barcelona (1908). Finalmente, cruza el Atlántico por última vez cuando lo ubicamos junto a su familia en Nueva York, de acuerdo con el censo poblacional de 1910 .

\footnotetext{
${ }^{69}$ Sobre las referencias bíblicas en su obra, véase el reciente estudio de Martínez (2006).

70 "el vino no es un alcohol".
} 
Al paso del tiempo, Darío continuó en Europa, hasta que desembarcó en Nueva York, durante el viaje de regreso a su país en el otoño de 1914, por motivo de una invitación del bibliófilo hispanista y fundador de la Hispanic Society of America, el Sr. Archer Milton, quien le organiza una agenda de charlas y banquetes. En una prolongada estadía que se extendió hasta la primavera de 1915, Darío enferma en noviembre y es atendido en el Hospital Francés (Torres, 1980: 850-860), clínica fundada por el cirujano y líder político Dr. José Julio Henna, amigo de Núñez y José Martí. Sin embargo, no se ha podido documentar en los periódicos, las revistas locales ni en otras fuentes si durante esta visita hubo otro posible encuentro entre el poeta y el músico. La crema y nata de la colonia hispanoamericana de Nueva York se hace presente cuando Darío lee su poema "Pax" en el salón Havemeyer de la Universidad de Columbia, el 4 de febrero de 1915; pero el nombre de Núñez no aparece entre los invitados más prominentes (Torres, 1980: 875). Cuando Núñez muere el 1 de octubre de $1915,{ }^{71}$ Darío se encuentra en Guatemala, como invitado y víctima del dictador Estrada Cabrera.

A la manera de una sonata, después de la exposición, desarrollo y recapitulación, cerramos el artículo con una coda o codetta, cuyo fin es indicar que la documentación identificada y mostrada aquí ofrece amplias oportunidades a futuros investigadores para el estudio de los escritos del poeta nicaragüense junto con los del puertorriqueño, conscientes de la mutua confianza, respeto y amistad que compartieron durante un corto, pero significativo periodo que comprendió su estancia en Lutecia. Admitimos que Darío, incitado por su colega, escucha, recibe y se ve impulsado a publicar una versión muy singular, basada en las doctrinas de Swedenborg, la Biblia y ciertas revelaciones divinas, pero lo hace con modestia y sin ningún otro motivo que el de presentarlas a nombre de un ser que considera íntegro, serio, sincero y genuino: "Yo no entiendo de todos esos bemoles, pero ciertamente, no es un espíritu común, ni mucho menos, un fumista" (Darío, 1977: 88).

\section{Bibliografía}

"A new pianist"

New York Times (12 de diciembre de 1877), 58.

Acereda, Alberto

"Dos caras desconocidas de Rubén Darío: el poeta masón y el poeta inédito", en Hispania, volumen 88, número 3 (septiembre de 2005), 423-444.

${ }^{71}$ Bureau of Records, New York City, Standard Certificate of Death. Register no. 28454. 


\section{Alberto Hernández-Banuchi}

AguirRe, Julián

"Cosas de Orfeo: A propósito de una nueva teoría musical", en La Nación (22 de mayo de 1901), 4 .

Balzac, Honoré

Louis Lambert, en Euvres complètes de H. de Balzac. Volumen 16. Paris: A. Houssiau, 1855, 109-207.

BLOY, Léon

Fournal inédit, II, 1896-1902. Lausanne: L'Âge d'Homme, 2000.

Callejo y Ferrer, Fernando

"Gonzalo Núñez: pianista-compositor", en Fernando Callejo y Ferrer, Música y músicos portorriqueños. San Juan, Puerto Rico: Cantero Fernández \& Co., 1915, 135-138. Consultado en: https://www.gutenberg.org/ebooks/43400 [20/02/2020].

Churton, Tobias

Occult Paris: The Lost Magic of the Belle Époque. Rochester, Vermont: Inner Traditions, 2016.

Couet, Lydia

"Marcel Réja: médecin, poète symboliste et historien de l'art asilaire", en Sociétés et Représentations, número 41 (2016/1), 229-246.

DARío, Rubén

Peregrinaciones. Madrid: Vda. de Ch. Bouret, 1901.

"Los diplomáticos poetas. - Amado Nervo. - Primer secretario de la legación de Méjico en Madrid”, en La Nación (14 de agosto de 1909), 5.

Todo al vuelo. Madrid: Renacimiento, 1912.

La vida de Rubén Darío escrita por él mismo. Barcelona: Casa Editorial Maucci, [1915]. Consultado en: http://www.cervantesvirtual.com/obra/la-vida-de-ruben-dario--0/ [28/01/2020].

"Cosas de Orfeo: Teología artística. Una nueva teoría musical”, en La Nación. Buenos Aires (28 de abril de 1901), en Rubén Darío. Escritos dispersos de Rubén Dario: recogidos de periódicos de Buenos Aires. Tomo 2. Edición de Pedro Luis Barcia. La Plata: Universidad de la Plata, 1977, 88-93.

La caravana pasa. Libro Primero. Edición crítica, introducción y notas de Günther Schmigalle. Managua/Berlín: Academia Nicaragüense de la Lengua/Tranvía, 2000.

"Pianos y pianistas", en Rubén Darío. Crónicas desconocidas, 1901-1906. Edición de Günther Schmigalle. Managua/Berlín: Academia Nicaragüense de la Lengua/Tranvía, 2006, 261274. 


\section{Núñez, Darío y el manuscrito Los arcanos de la música}

Novelas. Edición de Pably Kraudy y Jorge Eduardo Arellano. Managua: Banco Central de Nicaragua, 2017.

Docteur, Carlos

Historia anecdótica de la música y de los grandes músicos. París: Librería de la Vda. de Ch. Bouret, 1901 .

Durán, Manuel

Genio y figura de Amado Nervo. Buenos Aires: Editorial Universitaria, 1968.

"Gonzalo Núñez"

Le fournal (3 de junio de 1900), 5.

Hernández Banuchi, Alberto

"Gonzalo Núñez: arcano de la música", en Revista Universidad de América, año 2, número 2 (diciembre de 1990), 29-37.

"Un cuarteto parisino: Rubén Darío, Amado Nervo, Henry de Groux y Gonzalo Núñez", en Revista del Instituto de Cultura Puertorriqueña, año 6, número 13, segunda serie (2006), 86-99.

MACLEOD, Beth Abelson

Fannie Bloomfield-Zeisler. The Life and Times of a Piano Virtuoso. Urbana: University of Illinois Press, 2015.

MARTí, José

"Reseña de la Revista Universal, México, June 12, 1875", en José Martí. Obras Completas. Edición crítica. Tomo 3 "1875-1876 México". La Habana: Centro de Estudios Martianos, 2010, 71. Consultado en: http://www.josemarti.cu/obras-completas/tomo-3/ [01/03/2020].

Martínez, José María

"La Biblia como intertexto en el Modernismo hispanoamericano", en Daniel Attala y Geneviève Fabry (editores). La Biblia en la literatura hispanoamericana. Madrid: Trotta, 2016, 225-254.

Meléndez, Concha

"La voz de la Biblia en Rubén Darío", en Concha Meléndez. Antología y cartas de sus amigos. Selección y prólogo de Mariano A. Feliciano Fabre. San Juan, Puerto Rico: Cordillera/ Universidad de Puerto Rico, 1995, 152-171.

Méndez y Bejarano, Mario

Historia de la filosofia en España hasta el siglo Xx. Madrid: Renacimiento, 1927.

Methuen-Campbell, James

"Chopin in Performance", en Jim Samson (editor). The Cambridge Companion to Chopin. Cambridge: Cambridge University Press, 1992, 194-196. 


\section{Alberto Hernández-Banuchi}

Nervo, Amado

Obras completas. Madrid: Aguilar, 1967, 2 tomos.

NúÑEz, Gonzalo de J.

Los arcanos de la música. Manuscrito inédito. Archivo de la Música y Sonido del Archivo General de Puerto Rico en San Juan, sin fecha, caja 34.

Mazurka para piano. New York: Schirmer, 1891. Copia digital en: https://imslp.org/wiki/ Mazurka_for_piano_(Núñez\%2C_Gonzalo_de_Jesús)

“Tarjeta de visita”, enviada a Rubén Darío (3 de marzo de 1903a). Biblioteca Hispánica AEcid: Agencia Española de Cooperación Internacional para el Desarrollo, Archivo personal de Rubén Darío. Consultado en: UNEhttps://hispana.mcu.es/es/registros/registro. do?idBib=28903525\&tipoRegistro=MTD [15/01/2020].

"Carte postale", a Monsieur Rubén Darío (22 de abril de 1903b). Biblioteca Hispánica AEcid: Agencia Española de Cooperación Internacional para el Desarrollo, Archivo personal de Rubén Darío. Consultado en: https://hispana.mcu.es/es/registros/registro.do? $\mathrm{idBib}=28903524 \&$ tipoRegistro=MD [14/01/2020].

Oviedo Pérez de Tudela, María Rocío

"Biografía de Amado Nervo," en Biblioteca Virtual Miguel de Cervantes. Consultado en: http://www.cervantesvirtual.com/portales/amado_nervo/autor_apunte/ [12/03/2020].

Parrondo García, Arturo

"Páginas de sombra y espanto: Rubén Darío y el pintor Henry de Groux", en Anales de Literatura Hispanoamericana, número 46 (2017), 131-143.

Pougin, Arthur

"Les concours du Conservatoire", en La Chronique Musicale, tomo I, número 4 (15 de agosto de 1873), 145-153.

Ramírez, Serafín

La Habana artística: apuntes históricos. La Habana: Imp. del E. M. de la Capitanía General, 1891.

Ramírez, Sergio

"En el rincón de un quicio oscuro", en Cuadernos Hispanoamericanos, volumen 743 (2012), 79-92.

RolLAND, Romain

"Causerie musicale", en L'Art Dramatique et Musical au XXe Siècle. Annuaire International des Artistes et des Euvres (enero de 1903), 11-14.

Schmigalle, Günther

"La supuesta visita de Darío a Lourdes", en Revista de Temas Nicaragüenses, número 94 (febrero de 2016), 71-75. 
SÉrié, Pierre y Étienne JARDiN

"La 'Guerre du concerto' dans la presse française", en Alexandre Dratwicki (coordinateur). Le concerto pour piano français à l'épreuve des modernités. Arles: Actes Sud/Palazzetto Bru Zane, 2015, 301-397.

TORRes, Edelberto

La dramática vida de Rubén Darío. Edición definitiva, corregida y ampliada. San José de Costa Rica: EDUCA, 1980.

VALLE, Adrián del

"Crónicas de Arte: Gonzalo de J. Núñez", en Cuba y América: Revista Ilustrada. Habana, número XIX (23 de julio de 1905), 15 [incluye partitura de la mazurca 'María-Teresa', 311-312].

\section{Vogel, Benjamin}

The Piano after 1850. The Piano in Polish Collections. Cracovia: Institute of Music and Dance. Consultado en: http://www.piano.instruments.edu.pl/en/history/the-piano-after-1850 $[01 / 03 / 2020]$. 